\author{
Котов А.С. • Пантелеева М.В. • Мухина Е.В. ${ }^{1}$
}

Котов Алексей Сергеевич - д-р мед. наук, доцент, профессор кафедры неврологии факультета усовершенствования врачей, заведующий отделением неврологии по разделу «Наука»'; ORCID: https://orcid. org/0000-0003-2988-5706

129110, г. Москва, ул. Щепкина, 61/2-10, Российская Федерация.

Тел.: +7 (926) 2848115.

E-mail: alex-013@yandex.ru

\section{Пантелеева Маргарита}

Владимировна - д-р мед. наук, ст. науч. сотр. отделения неврологии'

Мухина Евгения Вадимовна - мл. науч. сотр. отделения неврологии'; ORCID: https://orcid.org/0000-0002-81457023

1 ГБУЗ МО «Московский областной научно-исследовательский клинический институт им. М.Ф. Владимирского»; 129110, г. Москва, ул. Щепкина, 61/2, Российская Федерация
Демиелинизирующие заболевания относятся к числу аутоиммунных патологий, основным патоморфологическим проявлением которых служит разрушение миелина в центральной нервной системе (ЦНС). В последнее время отмечается непрерывный рост демиелинизирующих заболеваний ЦНС, в том числе в детской популяции. Несмотря на активное развитие методов диагностики и верификации форм демиелинизирующих заболеваний, по-прежнему остается актуальной проблема дифференциальной диагностики демиелинизирующих заболеваний и других состояний, связанных с изменением структуры белого вещества головного мозга, выявляемым с помощью магнитно-резонансной томографии. Нами было обследовано 123 пациента с подозрением на демиелинизирующие заболевания ЦНС, диагноз подтвержден у 102 из них. Самой частой формой демиелинизирующих заболеваний ЦНС был рассеянный склероз - у 79 из 102 пациентов, намного реже встречались анти-MOG-ассоциированные расстройства - у 5 , заболевания из спектра оптиконевромиелита у 3, острый рассеянный энцефаломиелит - у 2. В лекции охарактеризованы основные клинические, лабораторные и нейровизуализационные особенности каждой из этих нозологий, освещены основные трудности в лечении педиатрических пациентов с демиелинизирующими заболеваниями ЦНС.

Ключевые слова: демиелинизация, дети, рассеянный склероз, оптиконевромиелит, анти-MOG

Для цитирования: Котов AC, Пантелеева MB, Мухина ЕВ. Демиелинизирующие заболевания центральной нервной системы у детей: лекция для практикующих педиатров. Альманах клинической медицины. 2021;49(3):239-244. doi: 10.18786/20720505-2021-49-034.

Поступила 26.02.2021; доработана 17.06.2021; принята к публикации 21.06.2021; опубликована онлайн 06.07.2021

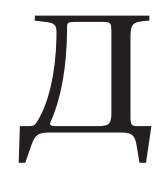
емиелинизирующие заболевания относятся к числу аутоиммунных патологий, основным патоморфологическим проявлением которых служит разрушение миелина в центральной нервной системе (ЦНС), и представляют собой одну из наиболее социально и экономически значимых проблем современной неврологии в связи с актуальностью вопроса их своевременной диагностики и последующей тактики ведения пациентов.

В последнее время отмечается непрерывный рост демиелинизирующих заболеваний 


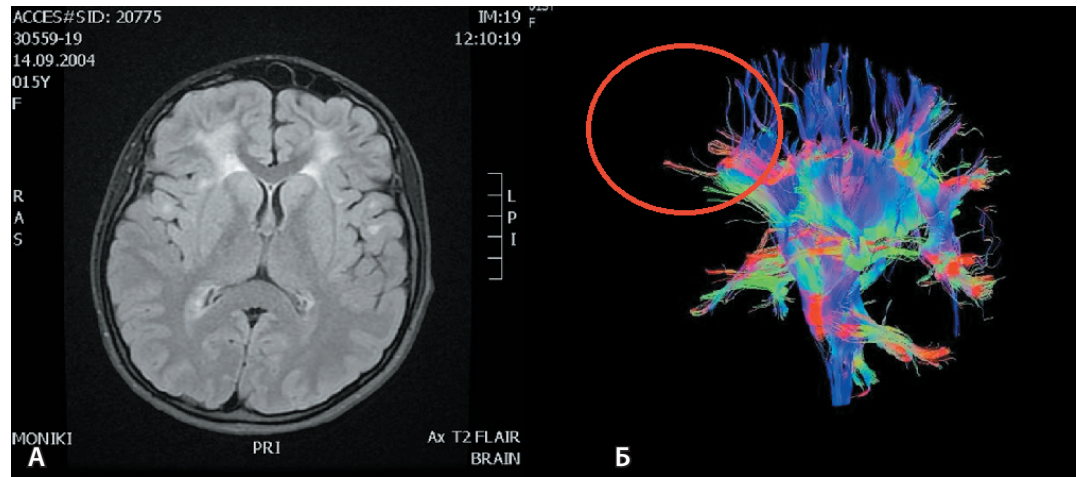

Рис. 1. Поражение белого вещества головного мозга у пациентки с генетически подтвержденной болезнью Александера: А - в режиме FLAIR визуализируется характерное двустороннее симметричное непрогрессирующее поражение белого вещества передних отделов гемисфер мозга, Б - на трактографии отображено обеднение количества волокон в лобных отделах (обведено красным)

ЦНС, в том числе в детской популяции. С одной стороны, это связано с улучшением диагностики: более широкой доступностью магнитно-резонансной томографии (МРТ), наличием специализированных кабинетов и центров рассеянного склероза (РС). Вместе с тем в российских реалиях эти кабинеты и центры созданы для диагностики и лечения РС у взрослых (заболевание включено в список «высокозатратных нозологий»), тогда как специалистов по педиатрическому РС можно пересчитать по пальцам. С другой стороны, наблюдается фактический рост частоты демиелинизирующих заболеваний ЦНС, обусловленный этиопатогенетическими особенностями данного континуума нозологий. При этом в значительной степени этиология и патогенез демиелинизирующих заболеваний ЦНС, за исключением редких семейных форм, остаются непонятными современной науке, что не позволяет добиться явного прорыва в их лечении по сравнению с «классическими» детскими инфекциями (корь, дифтерия, коклюш и др.), заболеваемость и смертность от которых после введения всеобщей вакцинации снизились в тысячи раз.

Спектр специфических лабораторных исследований, которые помогают

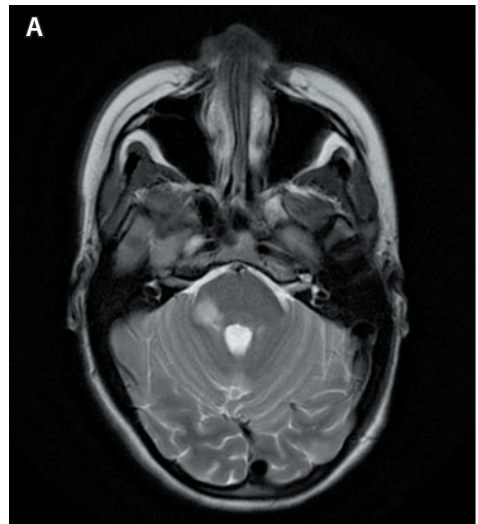

A

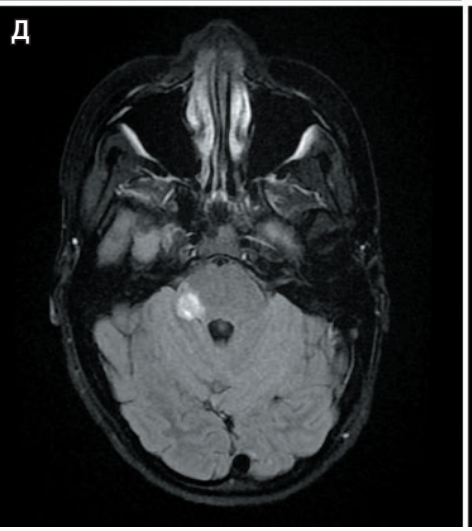

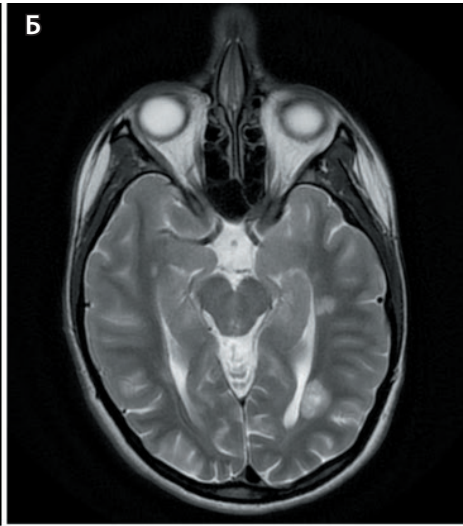

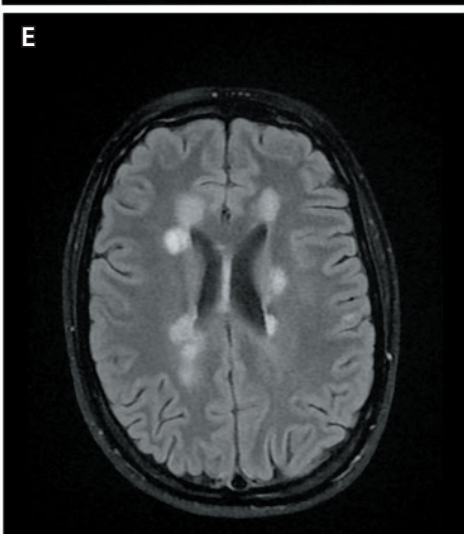

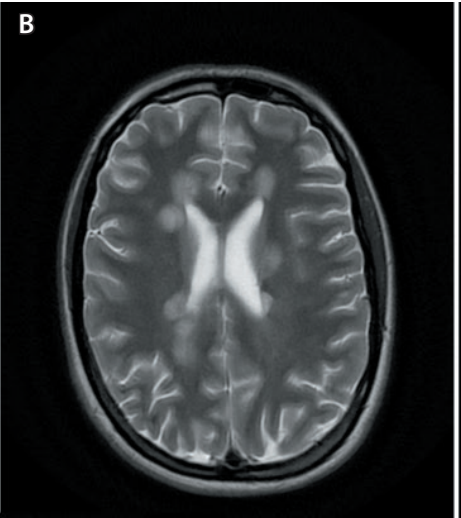

Ж

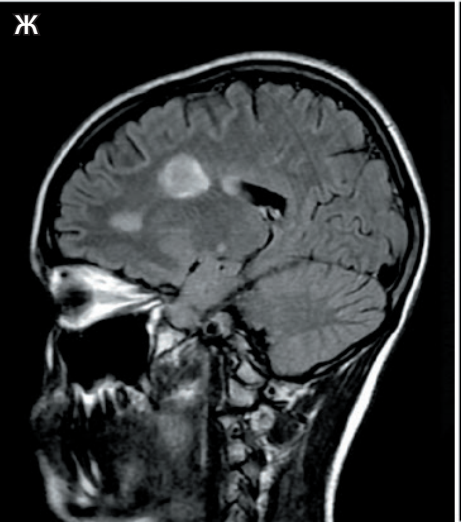

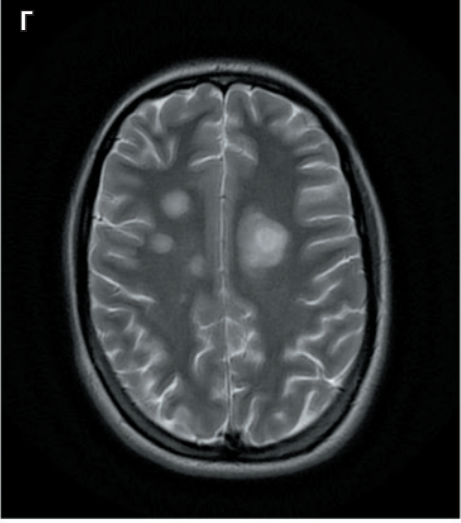

3

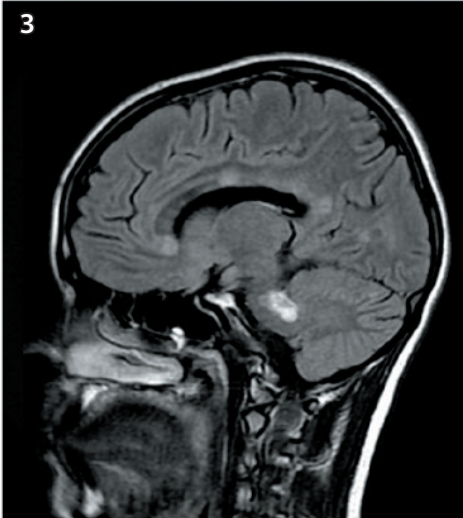

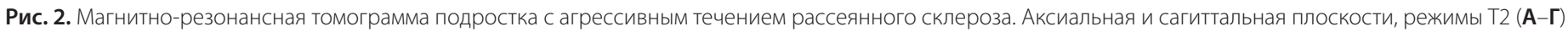

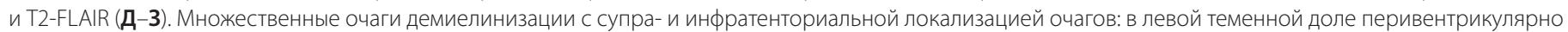

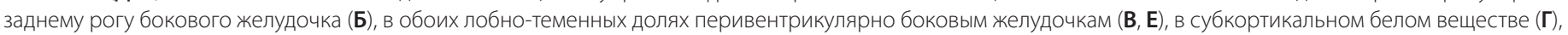
максимальными размерами до $23 \times 22$ мм (Ж), в своде и колене мозолистого тела (3), в основании правой средней мозжечковой ножки мозжечка (А, Д) 

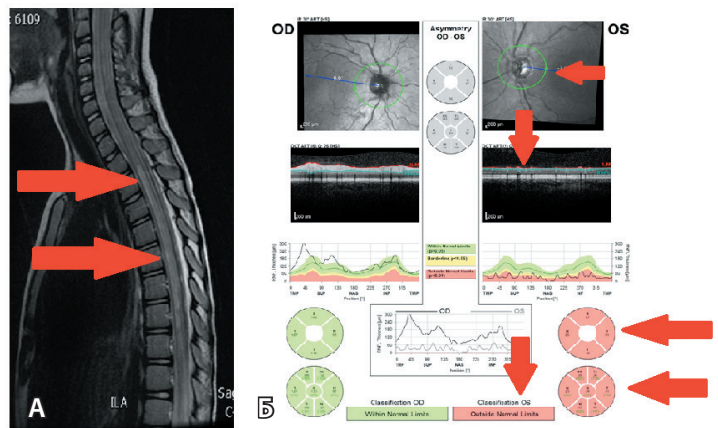

Рис. 3. Миелит и оптический неврит у ребенка 6 лет с оптиконевромиелитом: A - протяженный очаг миелита в грудном отделе позвоночника (указан стрелками), Б - атрофия левого зрительного нерва в результате оптического неврита по данным оптической когерентной томографии (указана стрелками)

в дифференциальной диагностике различных типов демиелинизирующих заболеваний ЦНС, в последние годы значительно расширился. Для подтверждения диагноза РС доступен анализ на определение типа синтеза олигоклональных антител [1], для подтверждения диагноза расстройств спектра оптиконевромиелита - аутоантител к белку водопроводящих каналов клеточных мембран олигодендроцитов, мишенью для которых выступает белок аквапорин-4 [2], для оптикомиелита, ассоциированного с анти-MOG-антителами, - антител к гликопротеину миелина олигодендроцитов $[3,4]$.

Несмотря на активное развитие методов диагностики и верификации форм демиелинизирующих заболеваний, по-прежнему остается актуальной проблема их дифференциальной диагностики с другими заболеваниями, связанными с изменением структуры белого вещества головного мозга, выявляемым на МРТ. Так, на «неврологические койки» педиатрического отделения ГБУЗ МО МОНИКИ им. М.Ф. Владимирского за 2016-2020 гг. поступило 123 пациента детского возраста с подозрением на демиелинизирующие заболевания ЦНС. Помимо стандартного обследования (анализы крови и мочи, электрокардиограмм и др.) всем пациентам проводили МРТ головного мозга (при необходимости - шейного и/или грудного отдела позвоночника) на высокопольном магнитно-резонансном томографе 1,5 Тл с определением наличия магнитно-резонансных критериев диагностики РС Макдональда [5], специфические лабораторные тесты (определение типа синтеза олигоклональных антител, антитела к аквапорину-4, антитела к MOG), оценку по расширенной шкале инвалидизации EDSS (Expanded Disability Status Scale) [6].

B результате диагноз демиелинизирующих заболеваний ЦНС не был подтвержден у 21 пациента. В 14 случаях это были пациенты со случайно выявленными на МРТ очагами в белом веществе, которые трактовали как постгипоксические изменения головного мозга. Поводом для проведения у них МРТ послужили неспецифические жалобы (головная боль, утомляемость и др.). Отсутствие органического неврологического дефицита, прогрессирования симптомов (как клинических, так и нейровизуализационных), а также наличие первого (не патологического) типа синтеза олигоклональных антител позволили с высокой степенью уверенности отклонить диагноз демиелинизирующих заболеваний ЦНС у данной когорты пациентов. У остальных 7 больных из этой группы были констатированы последствия вирусного энцефалита (4 человека), новообразования (1 человек) и редкие генетические заболевания с поражением белого вещества - атрофия Лебера и болезнь Александера (2 человека) (рис. 1).

Среди 102 пациентов с подтвержденным диагнозом демиелинизирующих заболеваний ЦНС основную долю составили больные РС (79 человек). Трое обследованных с ретробульбарным

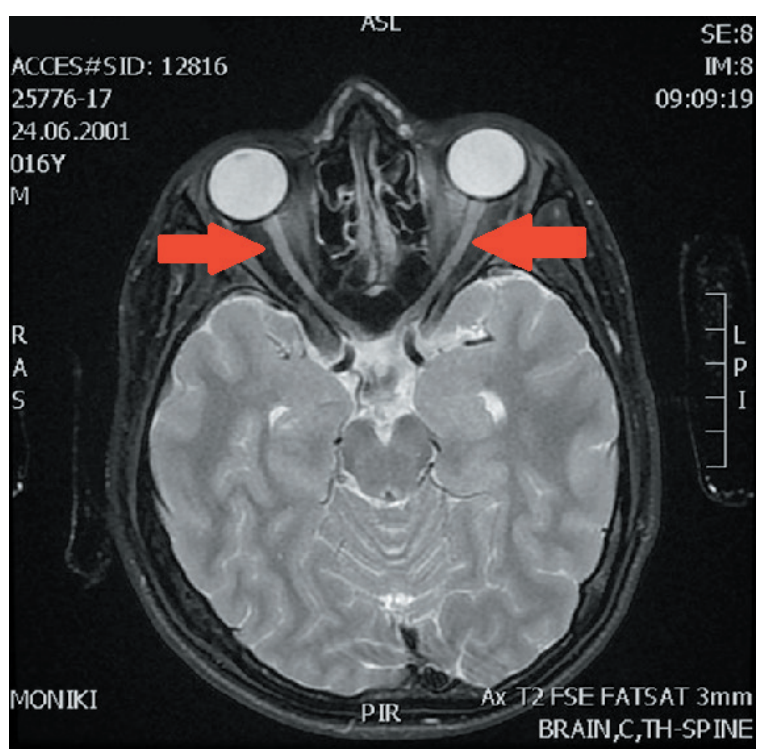

Рис. 4. Двусторонний оптический неврит у подростка 17 лет с синдромом анти-MOG. Режим Т2 с подавлением сигнала от жира. Гиперинтенсивный сигнал на большом протяжении от проксимальных отделов обоих зрительных нервов (указано стрелками) 


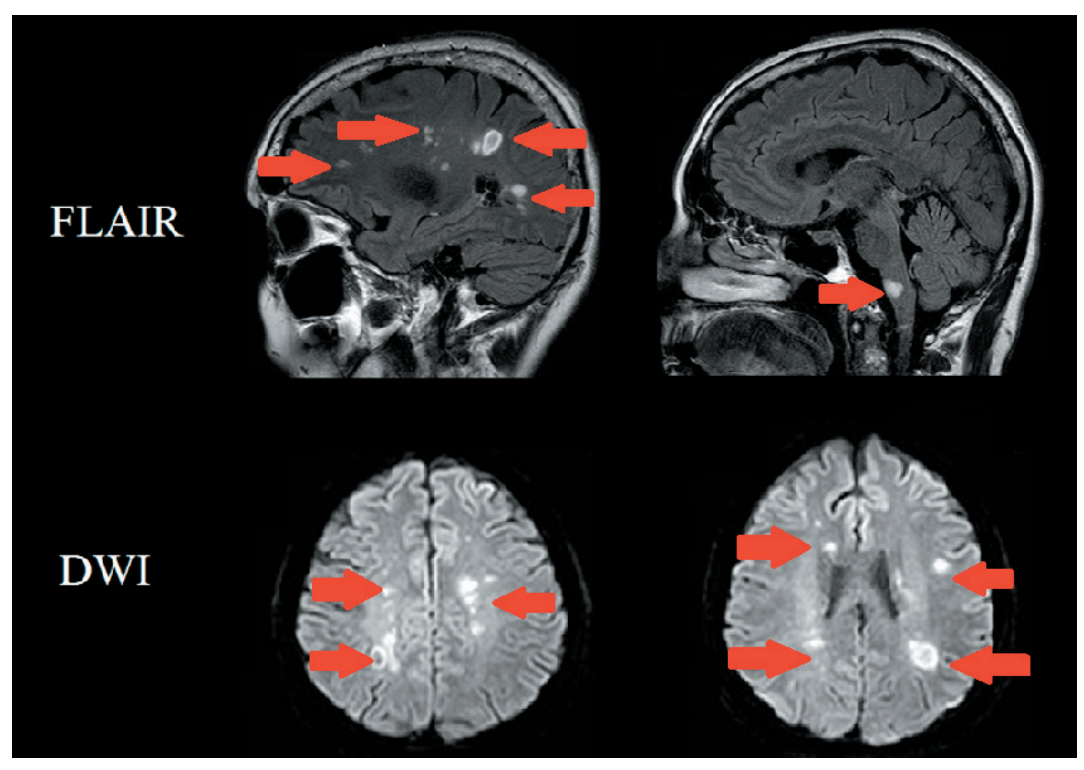

Рис. 5. Многоочаговое поражение головного мозга у подростка с острым рассеянным энцефаломиелитом. Крупные склонные к слиянию очаги в белом веществе больших полушарий, стволе мозга в режимах FLAIR и DWI (указаны стрелками), на месте «старых» очагов тут же образуются «новые», что нехарактерно для рассеянного склероза

невритом, трое с клинически изолированным синдромом и семеро с радиологически изолированным синдромом формально не соответствовали диагнозу рассеянного склероза, но имели крайне высокий риск эволюции своего состояния в достоверный РС.

Отметим: первоначально под наблюдением с диагнозом ретробульбарного неврита находились 9 детей, однако с течением времени (в среднем через 2,5-3 года от первых симптомов) заболевание развернулось в подтвержденный РС у 5 пациентов, и еще у 1 пациента - в оптикомиелит, ассоциированный с анти-MOG-антителами.

Интересным представляется случай ребенка из данной группы с первоначальным диагнозом радиологически изолированного синдрома, который находился под наблюдением более 4 лет. Клинических симптомов и распространения очагов во времени и пространстве, по данным MPТ, при наличии 2-го типа синтеза олигоклональных антител не наблюдалось. Развернутая клиническая и МРТ-картина проявилась спустя 4 года наблюдения, что позволило подтвердить диагноз РС и назначить специфическую терапию.

Типичными признаками РС у обследованных нами пациентов были эпизоды обострений с появлением новой неврологической заболеваниями симптоматики в различных системах (зрительной, двигательной, соматосенсорной и др.), что выражалось в нарастании балла инвалидизации по шкале EDSS на 1 и более, появлении новых очагов в белом веществе по данным МРТ, появлении «активных» (накапливающих контраст) очагов, второго (патологического, характерного для РС) типа синтеза олигоклональных антител (рис. 2).

Наличие антител к аквапорину-4 в крови у пациентов, перенесших единичные или повторные атаки оптического неврита и/или поперечного миелита, позволило установить диагноз расстройств из спектра оптиконевромиелита у 3 обследованных (рис. 3).

Нетипичное для РС клиническое течение и нехарактерные находки на МРТ, отсутствие второго типа синтеза олигоклональных антител и отрицательный результат теста на антитела к аквапорину-4 определяли показания к проведению анализа крови на антитела к гликопротеину миелина олигодендроцитов, что позволило подтвердить диагноз оптикомиелита, ассоциированного с анти-MOG-антителами, у 5 человек (рис. 4).

Возникновение симптоматики после перенесенной респираторной вирусной инфекции, грубые общемозговые нарушения (угнетение сознания, психические нарушения, эпилептические приступы), выраженный неврологический дефицит и характерная магнитно-резонансная картина (одновременное появление множества больших по размеру, склонных к слиянию очагов) позволили установить диагноз острого рассеянного энцефаломиелита у 2 обследованных (рис. 5).

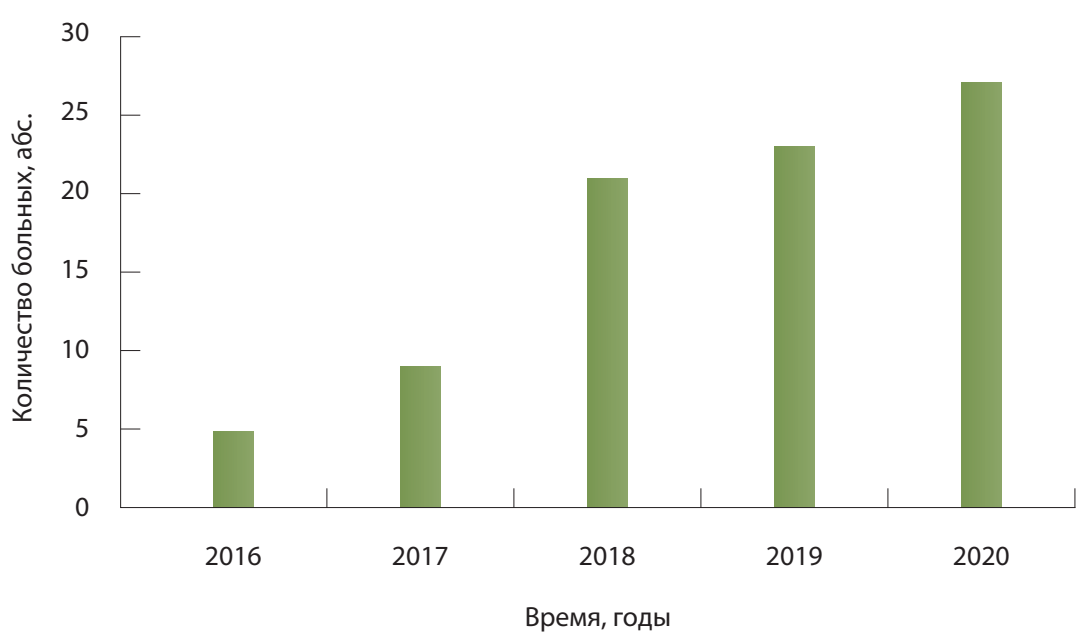

Рис. 6. Динамика выявления новых педиатрических пациентов с демиелинизирующими 
Актуальность проблемы демиелинизирующих заболеваний ЦНС у детей подчеркивает и динамика выявления новых пациентов: в 2016 г. было выявлено 5 больных с данным спектром нозологий, в 2017 - 8, в 2018 - 21, в $2019-23$, в $2020-27$ (рис. 6).

Таким образом, благодаря увеличению доступности МРТ растет как число выявленных случаев демиелинизирующих заболеваний ЦНС у детей, так и количество ложноположительных результатов, за которыми скрываются последствия перинатального поражения ЦНС или синдромальная генетическая патология. Сходные данные представлены Международной педиатрической исследовательской группой рассеянного склероза (International Pediatric Multiple Sclerosis Study Group, IPMSSG): в список состояний, которые могут имитировать острые воспалительные демиелинизирующие события, были включены другие воспалительные нарушения белого вещества, первичные опухоли в ЦНС и наследственные нейрометаболические заболевания $[7,8]$. Резидуально-органические заболевания ЦНС или последствия перинатального поражения ЦНС, согласно последним зарубежным данным, изначально не должны ассоциироваться с дебютом демиелинизирующих заболеваний ЦНС, так как для них характерны следующие признаки, нетипичные для демиелинизирующих заболеваний: задержка развития в анамнезе, прогрессирующая или резидуальная энцефалопатия, моноочаговое

\section{Дополнительная информация}

\section{Финансирование}

Работа выполнена по инициативе авторов без привлечения финансирования.

Конфликт интересов

Авторы декларируют отсутствие явных и потенциальных конфликтов интересов, связанных с содержанием настоящей статьи. поражение головного мозга по данным нейровизуализации [9].

Своевременное и правильное установление диагноза - лишь первый шаг на пути к помощи таким пациентам. Выбор препаратов для лечения РС у детей в России остается крайне ограниченным (большинство препаратов не одобрены у лиц младше 18 лет и очень дороги, что делает их применение офф-лейбл практически нереальным). Различные клинические исследования новейших препаратов не позволяют обеспечить всех реально нуждающихся пациентов из-за строгости критериев включения в эти исследования и их небольшого количества. Число препаратов для лечения заболеваний из спектра оптиконевромиелита еще более ограничено, в России все они без исключения назначаются офф-лейбл. Следует также еще раз подчеркнуть важность правильной диагностики: интерфероны, используемые для лечения РС, могут вызывать ухудшение у пациентов с оптиконевромиелитом [10]. Консенсусных клинических рекомендаций по лечению синдрома анти-MOG вообще не существует не только в России, но и на Западе [11].

Тем не менее последние научные открытия позволили сделать существенный шаг вперед в диагностике и лечении демиелинизирующих заболеваний ЦНС, в том числе у пациентов детского возраста. Очевидно, дальнейший принципиальный прогресс будет достигнут после фундаментальных открытий в области иммунологии и генетики. (⿻)

\section{Участие авторов}

А.С. Котов - концепция и дизайн исследования, анализ результатов, написание текста, редактирование рукописи; М.В. Пантелеева - сбор и обработка материала, написание текста; Е.В. Мухина - сбор и обработка материала, написание текста. Все авторы прочли и одобрили финальную версию статьи перед публикацией, согласны нести ответственность за все аспекты работы и гарантируют, что ими надлежащим образом были рассмотрены и решены вопросы, связанные с точностью и добросовестностью всех частей работы.

\section{Литература / References}

1.Puccioni-Sohler M. Cerebrospinal fluid oligoclonal lgG bands in multiple sclerosis: what does it mean? Arq Neuropsiquiatr. 2012;70(8):569-570. doi: 10.1590/ s0004-282x2012000800001.

2. Kira Jl. Unexpected exacerbations following initiation of disease-modifying drugs in neuromyelitis optica spectrum disorder: Which factor is responsible, anti-aquaporin 4 antibodies, B cells, Th1 cells, Th2 cells, Th17 cells, or others? Mult Scler. 2017;23(9):1300-1302. doi: $10.1177 / 1352458517703803$.

3. Ramanathan S, Dale RC, Brilot F. Anti-MOG antibody: The history, clinical phenotype, and pathogenicity of a serum biomarker for demyelination. Autoimmun Rev. 2016;15(4): 307-324. doi: 10.1016/j.autrev.2015.12.004.

4. Mariotto S, Ferrari S, Monaco S, Benedetti MD, Schanda K, Alberti D, Farinazzo A, Capra R, Mancinelli C, De Rossi N, Bombardi R, Zuliani L,
Zoccarato M, Tanel R, Bonora A, Turatti M, Calabrese M, Polo A, Pavone A, Grazian L, Sechi G, Sechi E, Urso D, Delogu R, Janes F, Deotto $L$, Cadaldini M, Bianchi MR, Cantalupo G, Reindl M, Gajofatto A. Clinical spectrum and IgG subclass analysis of anti-myelin oligodendrocyte glycoprotein antibody-associated syndromes: a multicenter study. J Neurol. 2017;264(12):2420-2430. doi: 10.1007/s00415017-8635-4. 
5. Polman $\mathrm{CH}$, Reingold SC, Banwell B, Clanet $\mathrm{M}$, Cohen JA, Filippi M, Fujihara K, Havrdova E, Hutchinson M, Kappos L, Lublin FD, Montalban $\mathrm{X}$, O'Connor $\mathrm{P}$, Sandberg-Wollheim $\mathrm{M}$, Thompson AJ, Waubant E, Weinshenker B, Wolinsky JS. Diagnostic criteria for multiple sclerosis: 2010 revisions to the McDonald criteria. Ann Neurol. 2011;69(2):292-302. doi: 10.1002/ ana.22366.

6. Kurtzke JF. Rating neurologic impairment in multiple sclerosis: an expanded disability status scale (EDSS). Neurology. 1983;33(11):14441452. doi: 10.1212/wnl.33.11.1444.

7. Wassmer E, Chitnis T, Pohl D, Amato MP, Banwell $B$, Ghezzi A, Hintzen RQ, Krupp LB, Makhani N, Rostásy $K$, Tardieu M, Tenembaum S, Waldman A, Waubant E, Kornberg AJ.
International Pediatric MS Study Group Global Members Symposium report. Neurology. 2016;87(9 Suppl 2):S110-S116. doi: 10.1212/ WNL.0000000000002880.

8. Wang CX, Greenberg BM. Pediatric Multiple Sclerosis: From Recognition to Practical Clinical Management. Neurol Clin. 2018;36(1):135149. doi: 10.1016/j.ncl.2017.08.005.

9. Tenembaum S, Chamoles N, Fejerman N. Acute disseminated encephalomyelitis: a long-term follow-up study of 84 pediatric patients. Neurology. 2002;59(8):1224-1231. doi: 10.1212/ wnl.59.8.1224.

10. Токарева ЮВ, Котов АС, Пантелеева МВ, Бунак МС. Расстройства из спектра оптиконевромиелита у пациентов детского возраста. Неврология, нейропсихиатрия, психосома- тика. 2018;10(1):60-64. doi: 10.14412/20742711-2018-1-60-64. [Tokareva YuV, Kotov AS, Panteleeva MV, Bunak MS. [Neuromyelitis optica spectrum disorders in pediatric patients]. Neurology, Neuropsychiatry, Psychosomatics. 2018;10(1):60-64. Russian. doi: 10.14412/20742711-2018-1-60-64.]

11. Бойко АН, Быкова ОВ, Сиверцева СА. Рассеянный склероз у детей и подростков. М.: Медицинское информационное агентСтво; 2016. 408 с. [Boyko AN, Bykova OV, Sivertseva SA. [Multiple sclerosis in children and adolescents]. Moscow: Meditsinskoe informatsionnoe agentstvo; 2016. 408 p. Russian.]

\title{
Demyelinating diseases of the central nervous system in children: lecture for practicing pediatricians
}

\author{
A.S. Kotov ${ }^{\prime}$ - M.V. Panteleeva' • E.V. Mukhina'
}

Demyelinating diseases (DD) are autoimmune disorders that morphologically manifest mainly with myelin destruction in the central nervous system (CNS). Recently, there has been a continuous increase in DD of the CNS, including those in the pediatric population. Despite the active development of strategies for the diagnosis of DD and verification of its forms, the differential diagnosis of DD and other diseases associated with abnormalities in the brain white matter structure on magnetic resonance imaging continues to be problematic. We examined 123 patients with suspected DD CNS. The diagnosis was confirmed in 102 of them. The most common form of DD CNS was multiple sclerosis found in 79 of 102 subjects. Much less frequent were anti-MOG-associated disorders (5 patients), neuromyelitis optica spectrum disorders ( 3 patients), and acute disseminated encephalomyelitis (2 patients). The main clinical, laboratory and neuroimaging characteristics of each of these disorders and the main difficulties in the treatment of pediatric patients with DD CNS are described.

Key words: demyelination, children, multiple sclerosis, neuromyelitis optica, anti-MOG

For citation: Kotov AS, Panteleeva MV, Mukhina EV. Demyelinating diseases of the central nervous system in children: lecture for practicing pediatricians. Almanac of Clinical Medicine. 2021;49(3):239-244. doi: 10.18786/2072-0505-2021-49-034.

Received 26 February 2021; 17 June 2021; accepted 21 June 2021; published online 6 July 2021

\section{Conflict of interests}

The authors declare no conflict of interests.

\section{Authors' contributions}

A.S. Kotov, the study concept and design, analysis of the results, text writing and editing; M.V. Panteleeva, data collection and management, text writing; E.V. Mukhina, data collection and management, text writing. All the authors have read and approved the final version of the manuscript before submission, agreed to be accountable for all aspects of the work in ensuring that questions related to the accuracy or integrity of any part of the work have been appropriately investigated and resolved.

Alexey S. Kotov - MD, PhD, Associate Professor, Professor of Chair of Neurology, Postgraduate Training Faculty; Head of Department of Neurology'; ORCID: https://orcid.org/0000-0003-2988-5706 $\triangle 61 / 2-10$ Shchepkina ul., Moscow, 129110, Russian Federation. Tel.: +7 (926) 2848115. E-mail: alex-013@yandex.ru

Margarita V. Panteleeva - MD, PhD, Senior Research Fellow, Department of Neurology ${ }^{1}$

Evgeniya V. Mukhina - Junior Research Fellow, Department of Neurology'; ORCID: https://orcid. org/0000-0002-8145-7023
${ }^{1}$ Moscow Regional Research and Clinical Institute (MONIKI); 61/2 Shchepkina ul., Moscow, 129110, Russian Federation 